\title{
A neuronal enhancer network upstream of MEF2C is compromised in patients with Rett like characteristics
}

\author{
Eva D'haene ${ }^{1, \dagger}$, Reut Bar-Yaacov ${ }^{2,3}$, Inbar Bariah²,3, Lies Vantomme ${ }^{1}$, \\ Sien Van Loo ${ }^{1}$, Francisco Avila Cobos ${ }^{1,4,5}$, Karen Verboom ${ }^{1,4}$, Reut Eshel ${ }^{2,3}$, \\ Rawan Alatawna ${ }^{2,3}$, Björn Menten ${ }^{1}$, Ramon Y Birnbaum ${ }^{2,3, *,+}$ and \\ Sarah Vergult ${ }^{1, *}$
}

${ }^{1}$ Center for Medical Genetics, Ghent University, 9000 Ghent, Belgium ${ }^{2}$ Department of Life Sciences, Faculty of Natural Sciences, The Ben-Gurion University of the Negev, 84105 Beersheba, Israel ${ }^{3}$ Center of Evolutionary Genomics and Medicine, The Ben-Gurion University of the Negev, 84105 Beersheba, Israel ${ }^{4}$ Cancer Research Institute Ghent (CRIG), 9000 Ghent, Belgium ${ }^{5}$ Bioinformatics Institute Ghent from Nucleotides to Networks (BIG N2N), 9000 Ghent, Belgium 


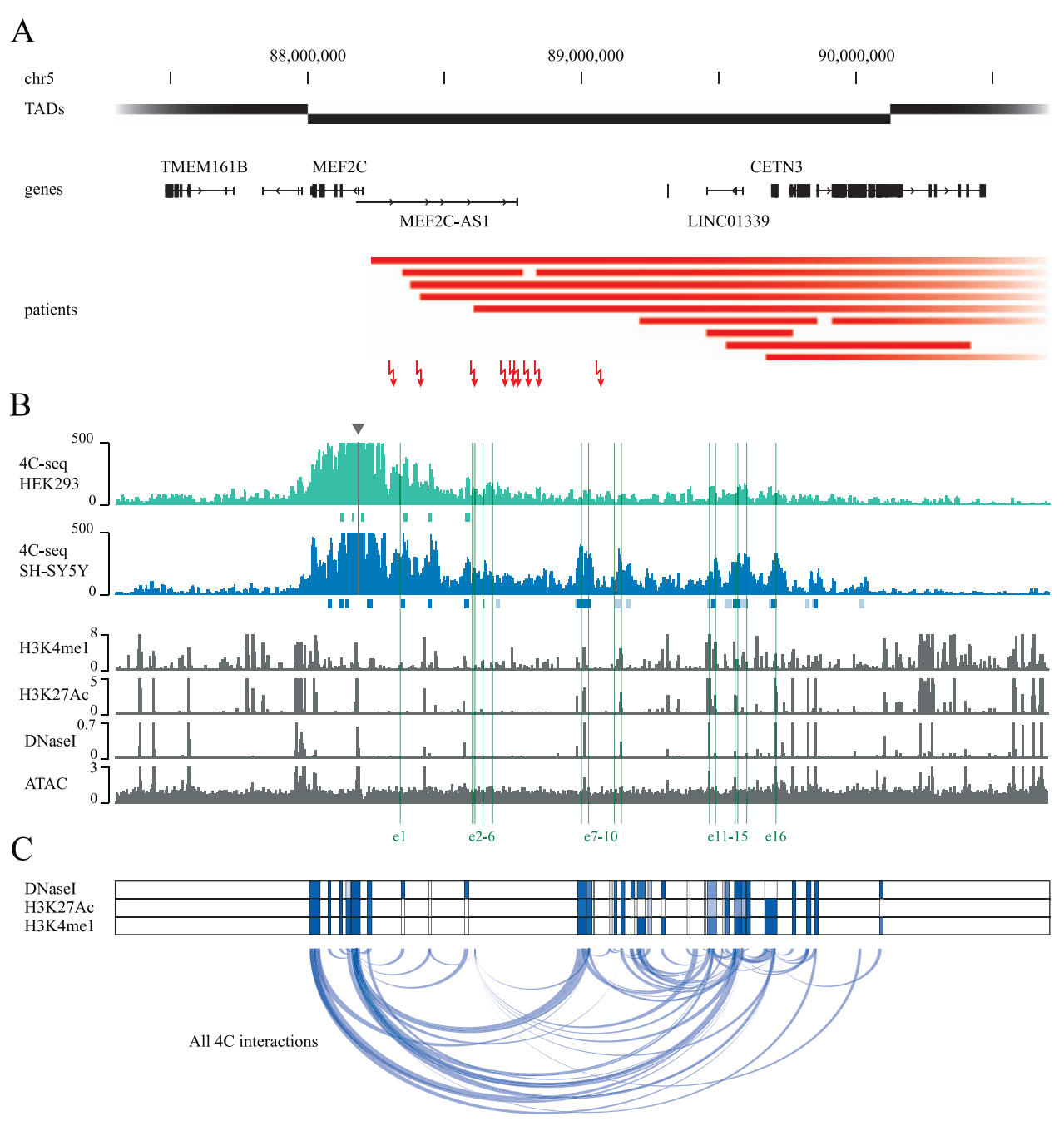

